\title{
Food Sovereignty for Food Security, Aquaponics System as a Potential Method: A Review
}

Ntobeko Mchunu*, Gareth Lagerwall and Adian Senzanje

Bioresources Engineering, School of Engineering, University of Kwa-Zulu-Natal, Pietermaritzburg, Republic of South Africa

\begin{abstract}
Aquaponic system is the innovative production of fish and plants at the same time in one circulating system. Aquaponic system is the quick emerging practice worldwide, particularly in the Republic of South Africa (RSA). There is little information, if any, that relates RSA with aquaponics system. As such, this literature review looked briefly in soilless systems setups that make up an aquaponic system. However, the focus was made on aquaponics system particularly, toward understanding the system operational, sustainability and suitability RSA. The literature also looked at potential method such as aquaponics system model development to kick start and optimise aquaponics system productivity in RSA. Food sovereignty through aquaponics system has a great potential to address food and nutrition insecurity in RSA.
\end{abstract}

Keywords: Aquaculture; Aquaponics; Hydroponics; Aquaponic model

\section{Introduction}

The increase in population and urbanization has resulted in increased need for food and water in South Africa [1,2]. In general, South Africa is a water and nutrient scarce country and there is a need to conserve this resource pool [3]. South Africa is one of the 30 driest countries in the world, with an annual average rainfall of less than 500 $\mathrm{mm}$, a significantly lower amount than the world annual averages of 860 $\mathrm{mm}$ [4]. South Africa's water resources are scarce and limited in extent. As a result, the International Water Management Institute (IWMI) has categorised South Africa a water stressed country [3].

Moreover, it has been proven that the continuous use of synthetic fertilisers over time depletes soil diversity which is needed for crop production [5] and challenges such as soil-borne diseases, weeds, and soil infertility, associated with soil plant production has made the soil culture risky and at times undesirable [6-8]. As a result of the need to produce more and good quality food, without further damage to the natural environment, there has been an exploration of soilless agricultural systems, most popular, these include aquaculture, hydroponic and recently aquaponics system [9].

Nitrogen $(\mathrm{N})$ and phosphorous $(\mathrm{P})$ are the main essential nutrients that are utilized in high quantities by aquatic organisms, particularly fish, to grow [10], and by plants to produce food [11]. However, these nutrients are becoming more and more limiting in agriculture as it is expected that in the near future phosphate rock will run out [12]. Similarly, the production of nitrogen fertilizers from atmospheric $\mathrm{N}$ is also expensive [13]. While biological $\mathrm{N}$ fixation has great potential, its use also requires other nutrients to grow the legumes [13]. Alternative sources of these nutrients need to be sought if sustainability is to be achieved [14].

It has been speculated and shown in most literature (of more than 25 year research by $[1,2,15-17]$, that the net nitrogen $(\mathrm{N})$ and phosphorous (P) concentration in the aquacultural effluent equals to the nutrient requirement of most vegetables, flowers and herbs, hence it is a potential nutrient source for plants [17]. This may pose a problem when disposed of in the environment. As a result, aquacultural waste and effluent runoff can contribute to negative environmental impacts associated with eutrophication, which affect fish well-being [2]. Eutrophication is the excessive richness of nutrients in lakes or in other water bodies, frequently due to run-offs from the land, which causes a dense growth of plant life [18].

Aquaponics combines aquaculture and hydroponic production systems into one system [19], and has been described as superior since it combines these two systems together [20]. Aquaponics is common and well known overseas being most popular in Australia [21]. However, aquaponics is still a new and emerging technology in most African countries, including South Africa. This opens a new niche for sustainable food production, which is necessary and important for South Africa to optimize it food availability. In order to make good use of aquacultural effluent and wastes, aquaponic systems have been designed with dual potential effect, (a) assist mitigate aquacultural fish waste product that has negative potential to the environment, and (b) to use nutrient-rich aquacultural effluent to produce healthy food $[22,23]$.

Aquaponic is the production of fish and vegetable at the same time through linking aquacultural fish waste to hydroponically growing plants as natural nutrient source material to support plant life cycle $[24,25]$. Aquaponics related benefits include the use of less water than conventional agriculture and in particular, provides an option for nutrient recycling and reuse [26]. This, in particular, is suitable and important for South Africa to address water scarcity and food insecurity problems.

South Africa is one of the nutrition insecure countries amongst others in Africa. Fish meat provides nutritious foods that contribute significantly to human well-being for active healthy life with related economic production [1]. However, in most rural areas of South Africa, freshwater fish and fish meals are not regarded as food or as a meal by the majority; rather it is discredited with related religious and cultural

${ }^{*}$ Corresponding author: Ntobeko Mchunu, Bioresources Engineering, Schoo of Engineering, University of Kwa-Zulu-Natal, P. Bag X01, Scottsville 3209 Pietermaritzburg, Republic of South Africa, Tel: +27 31260 1111; E-mail ntobeko.mchunuu@gmail.com

Received July 19, 2017; Accepted August 02, 2017; Published August 04, 2017

Citation: Mchunu N, Lagerwall G, Senzanje A (2017) Food Sovereignty for Food Security, Aquaponics System as a Potential Method: A Review. J Aquac Res Development 8: 497. doi: 10.4172/2155-9546.1000497

Copyright: $\odot 2017$ Mchunu N, et al. This is an open-access article distributed unde the terms of the Creative Commons Attribution License, which permits unrestricted use, distribution, and reproduction in any medium, provided the original author and source are credited. 
beliefs [27]. This is of a great concern because the majority of food and nutrition insecure people reside in rural areas, where the consumption and need for fish and fish meals is supposed to be high to combat food and nutrition security [1]. Hence, nutrition insecurity in S.A could be the result of limited fish inclusion in meals of most households. Hence, if people can own systems like aquaponics system food and nutrition insecurity can be addressed.

Hence, this study was conducted to understand aquaponics production with relation to South Africa and to study potential method to optimise these system productions for all people.

\section{Overview of Soilless Systems}

In soilless production, plants are raised without using soil as a growth medium, in most cases it is because of related soil infertility (low potential areas), erosion, adverse weather conditions and soil borne diseases problems associated with risk of field production [18]. The method of not using soil as a crop stand saves significant water because in soil systems water can leach to ground water [28]. There are various common and available soilless productions systems; these systems include hydroponic, aeroponics, aquaponics, vertical gardens and tunnel or greenhouse aquaculture culture [20]. Soilless production plays a critical and unique role in providing out of season food (meat and crop plants), herbs and flowers [29]. As a result, soilless systems have been a viable option to food and nutrition security in many countries including developing countries (Nigeria, South Africa and others) [8], however, there is little known or documented about these systems relating to Africa, particularly in Republic of South Africa (RSA). Hydroponic, tunnel aquaculture makes up the aquaponics system and has been individually the most adopted systems worldwide, with aquaponics system significantly lagging behind. This as a result suggest that aquaponics system is still an emerging practise particularly in RSA $[9,30]$. Aquaponics has proven to be superior over hydroponic and aquaculture because it combines these two systems as one system producing fish and plants at the same in a sustainable way.

\section{Hydroponics}

Hydroponics or hydroponic culture it where by plants are produced in a soilless growth medium where all mineral nutrients delivered to plants are first dissolved in water before nutrients are available to plants [8]. In summary, [29] in agreement with [9,31], described hydroponic as growing plants with nutrients and water without soil. There are two types of hydroponic systems that are usually in use, these are liquid and aggregate production systems [9]. The liquid hydroponic culture usually adopts nutrient film technique (NFT) (Figure 1), and DeepWater Culture (DWC)/floating rafts system (Figure 2) [7]. The growth medium hydroponic systems adopt various inert materials such as, pea gravel, perlite, peat moss, peat, sawdust, rock wool, coconut fiber, grow stones, oasis cubes, vermiculite, coarse sand and expanded clay pellets (Figure 3) [32].

\section{Aquaculture}

Aquaculture is the farming and husbandry of aquatic creatures under regulated or semi-regulated environmental conditions. These organisms may be fish, plants or shellfish (oysters), crabs, crawfish, shrimp, mussels and clams [1,2], looked at aquaculture from the point of a farmer and said aquaculture can be viewed as agriculture, where the farmer farms the water instead of the land. However, there has been an environmental concern associated with aquacultural effluent and wastes that it might contain significant nutrient, enough to cause eutrophication in waters bodies if disposed of in the environment which

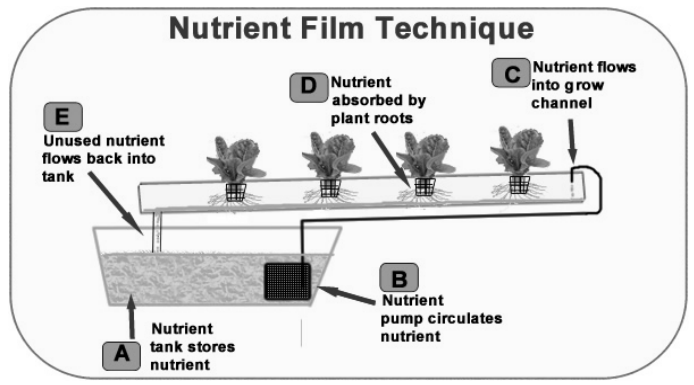

Figure 1: NFT system as plants grow and nutrient circulated in a thin film through plants roots (Shrethsa, 2010)

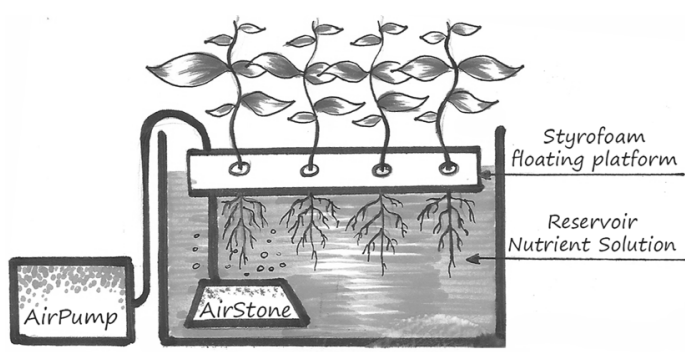

Figure 2: Floating raft system as plants grows on nutrient solution (Shrethsa, 2010).

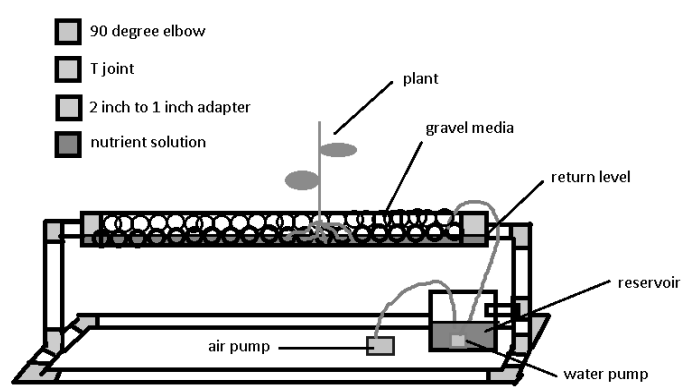

Figure 3: Growth medium bed system as plant raised in growth beds and nutrients circulated flow through the FAO [2]

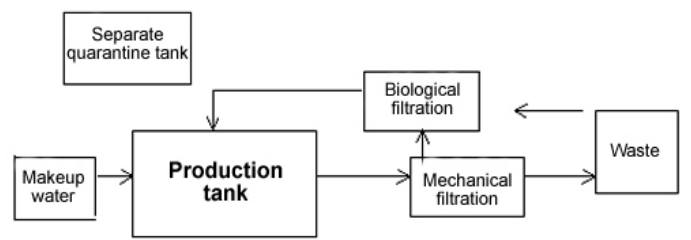

Figure 4: Recirculating aquaculture system as it relates to system setup and design.

could affect environmental sustainability and fish well-being (Figure 4) [33]. To address this, various filtering methods has been developed and tried in aquaculture to avert negative impact of aquacultural effluent wastes. This included, making and creation of wetlands using aquaculture waste [2], and the second fast growing filtering method suggested in aquaculture is aquaponic, circulating aquacultural waste as a nutrient source to growing plants in hydroponic culture (Figure 5) [34].

\section{Aquaponics system}

Most literature agrees that aquaponics is the production of fish and 
vegetable (fish and greens) at the same. This literature include [35] who defined aquaponics as a bio-integrated system that links recirculating aquaculture with hydroponic vegetable, flower, herb production (Figures 1 and 2), in the process saves significant quantity of water. This is also in agreement with [10] who had a similar definition of aquaponics but emphasized aquaponics system as a most sustainable and healthy production system comparatively. The aquaponic recirculating systems are designed to raise large quantities of fish in relatively small volumes of water (20kg of fish per 10001 volume of water), making aquaponics system a most innovative and ideal food producing method suitable to generation of today, also playing a critical role in agricultural evolution and advancement. In aquaponic system, effluent that is generated from the fish tanks is pumped and used to fertigate growth medium beds (GMB) in hydroponic culture [15]. In return, this process is worthy to the fish, because crop plants roots system together with rhizobacteria helps to extract available nutrients from water solution. The nutrients materials produced from fish algae, manure, and decomposing uneaten fish feed are pollutants that could build up to lethal levels in fish tanks, however, this instead waste serve as liquid mineral fertilizer in hydroponic culture [31]. The hydroponic culture function as a biofilter [36], removing off ammonia, nitrates, nitrites, and phosphorus and other trace elements, so the freshly cleansed water can then be recirculated back into the fish tanks [37]. The nitrifying bacteria living in the gravel and in association with the plant roots play a crucial role in nutrient cycling [14]. In the absence of these microorganisms the whole system would be dysfunctional [26]. Water is the most crucial input parameter of an aquaponic system, water is critical and essential component of an aquaponic system [38]. Even though fish is a water creature, a fish well-being could also be affected if water quality is poor [20]. In particular, a fish raised in recirculating tank culture, requires good water quality conditions since fresh water fish are very strict to environmental conditions (Figure 6) [39]. Hence, to maintain good water quality requires a testing kit, and this can be sourced from local aquacultural supply companies. Critical water quality parameters include dissolved oxygen (to be kept between the range of 4-8 mg/l),

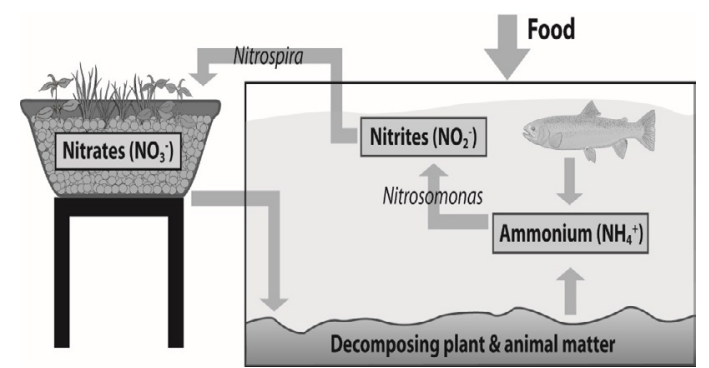

Figure 5: Aquaponic system as it relates to nutrient flow in the system [20].

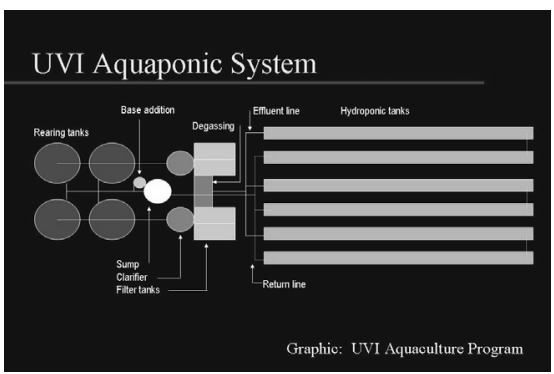

Figure 6: Aquaponic system showing the main component of the system and average dimensions [15]

\begin{tabular}{|c|c|c|}
\hline Vegetable type & Feed Rate Ratio $\left(\mathbf{g} / \mathbf{m}^{2} /\right.$ day) & Planting density $\left(\mathbf{p e r} \mathbf{~ m}^{2}\right)$ \\
\hline Leafy vegetable & $40-50$ & $20-25$ \\
\hline Fruiting & $50-100$ & $4-8$ \\
\hline
\end{tabular}

Table 1: Feed rate ratio and planting density [2].

carbon dioxide, ammonia, nitrate, nitrite (to be kept between the range of 3-100 mg/l), pH, chlorine, and other characteristics [2,37]. The stocking density of fish, the growth rate of fish, feeding rate and volume, and related environmental fluctuations can prompt rapid changes in water quality; as such a constant and vigilant water quality monitoring is very important to keep the system running smooth [40].

\section{Feed Conversion Ratios (FCR) and Species Combina- tion for Aquaponics System}

Feed Conversion Ratio (FCR) is defined as the amount of dry feed required to produce one $\mathrm{kg}$ of wet fish [41]. In agreement [41], who also defined FCR as the amount of food fish are able to convert into body mass and determine aquaponic system nutrient release over time. On average, fish are generally kept at $1 \mathrm{~kg}$ per $100 \mathrm{~L}$ tank which is equivalent to $10 \mathrm{~kg} / 1000 \mathrm{~L}$, this is a low stocking density, and this will convert to support approximately 20 lettuce plants in the hydroponic culture [24] Diverse types of fish species could be cultivated in controlled or regulated environment aquaponics system conditions [7]. The cold and warm water fish species are both promptly and easily adapted to recirculating aquaculture systems [17]. These fish species, includes tilapia, trout, catfish, arctic char, perch and bass [2]. However, the management and practices vary with the type of species raised, because different fish have different morphological and physiological environmental requirements [42]. The selection of plant species to adapt to the hydroponic culture in aquaponics greenhouses is determined by stocking density of fish tanks and subsequent nutrient concentration of aquacultural effluent [43] Vegetables such as herbs, lettuce, and specialty greens (chives, spinach, basil, and watercress) have low to medium nutritional requirements, are well adapted to aquaponics systems [21]. The crop plant that yields fruit such bell peppers, tomatoes and cucumbers have a higher nutritional demand and perform better in a heavily stocked and well established aquaponic system [44] (Table 1).

Most commercial aquaponic systems are based on tilapia production [38], tilapias are an ideal species because they mostly grow in temperatures that are similar to those required by the plants. They also grow fast and are tolerant to a wide range of environmental climatic conditions; this is what makes tilapia one of the most cultured fish across the world [45]. However, Barramundi and Murray cod fish species have been raised in recirculating aquaponic systems in Australia [7]. It is confirmed by various literatures, including over 25 years of research by James Rakocy at UVI that tilapias are the most farmed fish species [41]. Tilapia has been combined with most vegetables from the list including lettuce, cucumber, tomatoes, herbs and most of the other leafy and fruity vegetables, and has both performed outstandingly well in most cases [2].

\section{Tilapia production in South Africa}

Tilapia is the most farmed fish species worldwide. There are three most farmed fresh water tilapia species, these are Mozambique, Nile, and Blue Tilapia [45]. Tilapia is a warm-water species that grows well in a recirculating tank culture with tolerant to fluctuating water conditions such as $\mathrm{pH}$, temperature, oxygen, and dissolved solids, tilapia can tolerate as much as $\left(9^{\circ} \mathrm{C}\right.$ to $\left.42.5^{\circ} \mathrm{C}\right)$ water temperatures, dissolved oxygen as low as $0.1 \mathrm{mg} / \mathrm{l}$, and unionized ammonia concentration of $2.4 \mathrm{mg} / \mathrm{l}$, this explains why tilapias are the most farmed freshwater 
fish in the world $[41,46]$. Tilapia produces a white-fleshed meat rich in protein suitable to local and wholesale markets for easy availability and accessibility [1]. However, in South Africa Nile tilapias haven't been able to establish a viable population in most areas of the country. Tilapia requires an average temperature of $28^{\circ} \mathrm{C}$ ranging between within $26^{\circ} \mathrm{C}$ to $30^{\circ} \mathrm{C}[10]$. These conditions need to be present for at least 7.5 months to establish a viable economic population; this is not achievable with South African climatic conditions [47]. However, genetically improved tilapia that grows at an average rate of $2.75 \mathrm{~g}$ a day can be harvested within six months, still this is limited by colds winter of South Africa making the country nearly to impossible for a viable economic aquaculture production [48].

Nevertheless, the findings are exposing a research gap and the need for genetic engineering advancements in the field of aquaculture, particularly in RSA; to at least maximize fish growth within three to four months, to accommodate countries like South Africa (cool climate) to have the opportunity to achieve viable fish populations for economic production and sustainable fish production

\section{Method of Optimising Aquaponics System}

Feed conversion ratio (FCR) is very important in aquaponics system management because it determine nutrient balance, release and flow in the system. There are currently two scientifically proven approaches to address feed conversion ratios in aquaponics systems. The first model was developed by Rakocy from University of Virgin Island (UVI), and the model was named after him and his team- UVI/ Rakocy [6]. The nutrient flow approach was developed from more than 20 years of research in aquaponics by Rakocy [48]. He proved that fish produces significant quantities of nutrients particularly nitrogen and phosphorous which are important for plant production. However, fish have different nutrient requirements to plants, as such, waste produced will not fully support complete life cycle of growing plants, as a result, there will be a need to supplement other nutrients particularly trace elements. The significantly short mineral nutrients in the fish feed are $\mathrm{Ca}, \mathrm{K}$ and $\mathrm{Fe}$ to which these nutrients are significantly important for crop plant production.

The UVI approach was recently challenged and adopted by Lennard when he was conducting a Ph.D. study that sought to optimise aquaponic production in Australia. Out of series of scientific experiments, one of Lennard's Ph.D. outputs was the aquaponic model that predicted nutrient conversion of Murray cod for hydroponic production of vegetables [7]. Both the UVI and Lennard approaches agreed with each other, in that fish nutrient requirements are different from those of plants, and as such, when you try to balance one element others become short or in excess. Both approaches agree with each other that in order to achieve sustainable nutrient flow, other elements will need to be supplemented.

There is a clear scientific evidence that aquaponics system is a complicated system since balancing nutrients requires a sound simultaneous knowledge of two significantly different agricultural enterprises (fish and greens), as such in RSA if aquaponics system were to make different in people's lives there will be a need for extensive population training in order to make aquaponic system work, other options include developing an aquaponic system model with user interface inputs and implement outputs model recommendations.

\section{Nutrient Flow in Aquaponic System}

Fish waste produces significant quantity of ammonia-N and solids which have been shown to be nutrient rich, to which are important for plant production when dissolved in water in the fish tank [44]. However, in order for fish waste to be made available to most plants it must first to go through mineralization process [13]. Mineralization is the process by which organic matter (solids) breaks down in the environment (aquaponics) [48]. There are five main mechanisms that are responsible for mineralization, which in turn determines nutrient release pattern in the system in an aquaponic system; these mechanisms are ammonification, nitrification, denitrification, immobilisation and volatilisation [38]. Mineralization occurs quickly, less than a week (3-7 days) when conditions are perfect for bacteria to reproduce [49]. The conditions that favour optimum mineralization are high aeration, adequate moisture, appropriate $\mathrm{pH}$, and balanced mineral nutrients [50]. The environmental and grow media mineralogy factors affect the microflora players and their actions, which in turn determine the rate of mineralization in the system and thus the amount mineralized over time [13].

Microbial activity is limited at a temperature near freezing and at low $\mathrm{pH}$ less than 5.5 and increases with rising temperature and $\mathrm{pH}$. Maximum Nitrogen- $\mathrm{N}$ mineralization occurs when the temperatures in the system reach $30^{\circ} \mathrm{C}$ to $36^{\circ} \mathrm{C}$, however, the decline in $\mathrm{N}$ mineralization indicates low microbial activity and a degradation of the biological properties of the grow medium [30]. When temperature, moisture and $\mathrm{pH}$ is favourable for microorganisms to metabolize will results into Mineralization, the opposite of the process lead to immobilisation.

\section{Nitrification}

Nitrification is the transformation of $\mathrm{NH}_{4}^{+}-\mathrm{N}$ into $\mathrm{NO}_{3}^{-} \mathrm{N}$ [49]. The requirements for optimum nitrification rate include moisture (water), aeration (very critical in aquaponics system), alkaline $\mathrm{pH}$ ranges and warm temperature conditions [51]. There are two bacterias or microorganisms that contribute to nitrate- $\mathrm{N}$ formation (nitrification). These are Nitrosomonas europeana which oxidizes ammonium- $\mathrm{N}$ into nitrite- $\mathrm{N}$, nitrite- $\mathrm{N}$ is further oxidized by Nitrobacter winogradskyi into nitrate- $\mathrm{N}$ [48]. However, nitrification is inhibited at high temperature, high temperatures result into the availability of $\mathrm{N}$ as ammonia- $\mathrm{N}$. This then contributes significantly into increased ammonium-N volatilization and reduced nitrification rate [10], this is the important management factor in aquaponics system. The optimum temperatures for nitrification vary between $25^{\circ} \mathrm{C}$ to $30^{\circ} \mathrm{C}$ the $\mathrm{pH}$ for both processes is at 8.5 but steps differ with regards to their tolerance ranges, in acidic condition at $\mathrm{pH}$ less than 5.5 the nitrification is low and weak, which accounts for less nutrient availability [37]. Nitrification requires sufficient oxygen supply, this a very important management factor in aquaponics since water and suspended solids can suffocate the system [2]. Restricted aeration delays nitrification, oxygen determines the speed of the process, and metabolisms are increased with increase in oxygen to the bacteria's [21].

\section{Denitrification}

Denitrification is the gaseous loss of nitrogen to the atmosphere via a microbial respiration process [49]. This process occurs under anaerobic conditions where microbes obtain their $\mathrm{O}_{2}$ from $\mathrm{NO}_{2}-$ $\mathrm{N}$ and $\mathrm{NO}_{3}-\mathrm{N}$ with the associated release of $\mathrm{N}_{2}$ and $\mathrm{N}_{2} \mathrm{O}$ [30]. The environmental concerns about emission of nitrous oxides are mainly related to the effect on global warming and the role of nitrous oxides in ozone destruction [38]. The destruction of $\mathrm{O}_{3}$ is catalyzed by $\mathrm{NO}$, halogens, hydroxyl, and hydrogen [22]. A possible source of NO is from $\mathrm{N}_{2} \mathrm{O}$, the product of denitrification, which can diffuse into the upper atmosphere and lead to atmospheric holes, hence causing problems for plants and animal life well-being from excessive exposure to ultraviolet 
radiation [17]. As such, aquaponics too, has to avoid denitrification as much as possible to avoid these implications. It has been shown by [2], that the common management strategy is to select a best growing method (NFT, GMB and DWC) that will allow suitable condition for microbial growth and production in order to avoid denitrification $[6,7]$.

\section{Modeling Principles and Methods of Model Development}

Modeling is the simplified representation of a real system, in this case, aquaponic system, and it requires a complete understanding of systems processes [52]. In aquaponics, this includes processes such as nitrogen mineralization, nutrient flow in the system (fish to plant), and plant and fish ecosystem [53]. Aquaponic system can be very complex and sometimes imposable where there is a lack of expertise, because aquaponics requires a sound simultaneous understanding of two agricultural enterprise (fish and crop plants) ecosystems. Models help to outline, organize and represent thoughts and understanding into a form of computer model or software [54]. Models can act as a support tool for planning, decision making, and output forecasting, evaluating effects of climate change as well as for identifying research gaps [3]. As such, model has the capacity to help solve or simplify aquaponics system complexity for any ordinary person to use to benefit, hence, achieve related food security and economic production. However, model application varies with systems dynamics including changing land use and climates [55].

The use of models involves standard protocols, including defining the purpose (why adopting the study? and for whom to benefit?), selecting the model (selection of model is based on the initial purpose, whom are the end users?), collecting data, sensitivity analysis, calibration, and corroboration (testing), uncertainty analysis, scenario analysis, results in interpretation and communication of uncertainty and post audit, (Figure 7) [56,57]. This also suggests that even the aquaponic model that the study is envisaged to produce has too; go through all this process, to conform to be acceptable model. In following the modeling protocol, serves a number of benefits, it reduces potential modeler bias, providing a roadmap to be followed, allow others to assess decisions made in modelling, allow others to repeat the study, and improves the acceptance of model results [58].

During model development, there are three major procedural processes, these include, calibration, verification and validation.

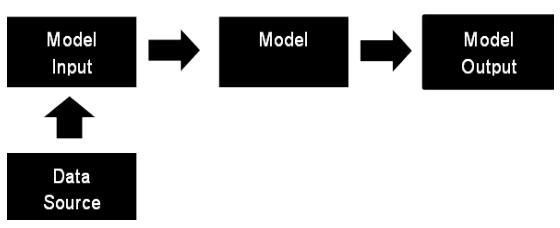

Figure 7: Model development frame work.

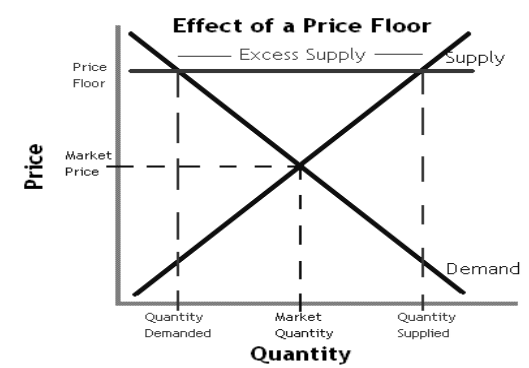

Figure 8: Law of demand and supply (Investopedia, 2016).
Calibration is the process of modification of the model parameters and imposing within the margins of the uncertainties (in model parameters and / or model forcing) to obtain a model representation of the processes of interest that satisfies pre-agreed criteria [55,59]. Verification is the process of confirming that a computer code correctly implements the algorithms that were intended [59]. Furthermore, [14] explained model verification as the process of determining that a model implementation accurately represents the developer's conceptual description of the model and the solution to the model. Validation is the process of confirming that the predictions of a code adequately represent measured physical phenomena [56]. In agreement with Daggupati [54], Arnold et al. [60] explained model validation as the process of determining the degree to which a model is an accurate representation of the real world from the perspective of the intended uses of the model.

The main purpose of the model is to assist and help solve social, economic and environmental issues [52]. However, depending on the purpose of the model design, meaning who are the targeted end users or beneficiaries of the model, which determines tools to be adopted or employed to create the model. It logical and make sense that, in situation where significant population beneficiaries lack expertise like RSA and Africa at large [61], it is advisable to adopt relatively simpler, user friendly and general or rather easily accessible software's such as Microsoft particularly excel which cooperate functions like VBA, Solver, dropdown list, cell locks, if statements, lookups functions, etc. In cases where the end user is highly educated such as scientist, engineers etc. tools such Java, Matlab, Python, C++ and many others, could be adopted.

\section{Sustainability of Aquaponics}

In general sustainability is the ability to maintain any system at a constant rate or level [62]. There are various definitions of sustainability across different schools of thought. In the school of environmental science, sustainability is defined as the quality of not being harmful to the environment or depleting natural resources and thereby supporting long-term ecological balance [63]. In economics, sustainability is defined as the use of various strategies for employing existing resources optimally so that a responsible and beneficial balance can be achieved over the longer term, including development activities which aim to ensure that countries produce operational profits allowing them to continue to function [14]. In sociology, sustainability is defined as the development activities that meet the needs of the present without compromising the ability of future generations to meet their own needs, a development activity which aims to ensure that people experience good social well-being [64].

Almost all sustainability definitions agrees that sustainability is the activities that will maintain a system at a constant level for a long run, be it a social, economic or environment system it does not matter (Figure 8). The derived definition agrees with the first general definition of sustainability, this validates that sustainability is to maintain a system well-being constantly over a long run.

\section{Environmental Sustainability}

Since 1990 there has been a growing concern of agricultural systems pollution, particularly to the environment [63]. The concern included water pollution by nitrates (a possible source of fertilizers run off), pesticides, erosion, greenhouse gas emission and biodiversity losses [63]. Over years, this has called for the development of guidelines and principles to assess the environmental sustainability components to monitor and control sustainable development progress [65]. 
The guideline included that; (a) spaces of natural imperative and biodiversity needs to be preserved; (b) the usage of renewable resources (e.g. raw materials which can be used such as water water) must be retained below the rate of natural replenishment or regeneration (c) the usage of non-renewable assets such as raw materials and fossil fuels, must be retained below the rate of potential growth in renewable resources, (d) at all impact of emissions and lethal materials on natural environment (soil, water, and climate) and human well-being must be reduced up to a safe level, lastly (e) the effect of environmental disasters must be reduced and environmental threats must only be recognized to the degree that, even in vilest case scenarios, no everlasting damage outliving one generation would be caused [66].

It is important to uphold and conserve the environment [47]. However, besides potential fertilizer runoff from agricultural land, there is a serious atmospheric concern with aquaponics. An aquaponic system is a bio-integrated food production system that produces meat and greens at the same time [6]. The success of aquaponic system relies on microorganism's community to transform nutrients and solid wastes into plant available [13]. In a typical aquaponic system denitrification usually occurs during mineralization and ammonium-N transformation process [49]. To avert this challenge of possible nitrogen toxicity, most aquaponic system instead of addressing denitrification, takes advantage of denitrification condition to remove excess nitrogen in the system, to an extent in that some aquaponic system creates denitrification condition for similar reasons [67].

The environmental concerns about denitrification are the emission of nitrous oxides which is mainly related to the effect on global warming and the role of nitrous oxides in ozone destruction [68]. The destruction of $\mathrm{O}_{3}$ is catalyzed by $\mathrm{NO}$, halogens, hydroxyl, and hydrogen, a possible source of $\mathrm{NO}$ is from $\mathrm{N}_{2} \mathrm{O}$, the product of denitrification, which can diffuse into the upper atmosphere and lead to atmospheric holes, hence causing problems for plants and animal life from excessive exposure to ultraviolet radiation [17]. Hence, aquaponics, when evaluated for environmental sustainability, has to be evaluated on the basis as well.

\section{Economic Sustainability}

The aquaponic system yields two enterprise products (meat and greens), and it is shown in the most literature that it is often difficult to manage and market these two distinctly different products [66]. In most cases, a farmer or growers decide at the beginning which enterprise he or she wants to focus on (fish only, plants only or both). There is a risk associated with opportunity cost, that a farmer or a grower can make a wrong choice of enterprise hence, abide to related loss effect. In a typical farmers market, farm gate prices change every day depending

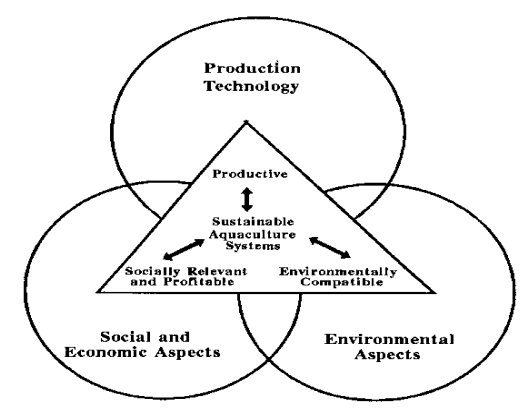

Figure 9: Sustainable aquaculture system as it relates to environment, economic and social system, flagging that, in order to attain sustainable aquaculture production other sustainability components needs to be attained as well [1]. on the demand and supply curve status, as such, this requires sound economic skills [21], (Figure 9). This clearly shows the difficult to run the aquaponic system; hence, if aquaponic economic sustainability is to be achieved, specific expertise is needed to make aquaponic profitable.

However, there are suggested guidelines to achieve a sound and acceptable economic sustainability. These are, (a) ranks of income and employment must be increased and maintained as required, with outstanding consideration given to socially and geographically satisfactory distribution, (b) it should be possible for productive capital, based on social and human capital, to be at least maintained and to show qualitative improvement, (c) economic capacity and competitiveness for innovation must be improved, (d) market instruments such as pricing must be the principal economic determinants, with outstanding considerations being given to scarceness factors and external cost lastly (e) the public sector must not be managed at the peril of future generations (e.g. failure to preserve assets, dept) [65].

Nevertheless, there is also the issue of generating the fish feed, some fish species are carnivorous, while others are herbivorous and others are omnivores. Carnivores are meat eating fish and they need at least $45 \%$ of the protein in their food, without which they become severely malnourished [15]. Herbivorous fish are those that will eat only plants and omnivorous fish are those that eat everything, opportunistic fish; their feeding behavior is based on the food available in that particular habitat but not limited to. The protein content for herb and omnivores are generally kept at $32 \%$ [7]. The related challenge is to select the best fish type according to the sustainability of the economic resources and factors (fish feed (protein source), market and price stability, politic stability, input cost, fixed cost etc) and to keep up with the standard guidelines of economic sustainability. While availability of fish feed in African countries is limited, there is also an issue of fish feed storage sustainability a critical matter, since fish feed is the main aquaponic input.

\section{Social Sustainability}

A significant effort in science regarding sustainability has been based on an environmental approach into solving problems [47] There is little information adopted by scientists in a social approach into solving scientific problems (integrational approach). This could be misleading in scientific research and research output that science produces every day [66]. There is a significant quantity of good scientific output (information) that could change the situations in the world. However, this information still remains in library shelves. This is because most of it cannot be implemented due to community dynamics that stands in the way, to which causes project failures [65].

This could be attributed to the lack of social approach integration in the science field, particularly in engineering science. For instance, best tools that can optimize production for local people are made available on a very complicated format like Java, $\mathrm{C}++$, Matlab and others, to which even some highly educated people cannot use or comprehend. The question is then, how much more for less literate ones? the ones who supposed to benefit the most [69]. Thus, suggest that if sustainability is to be achieved scientist needs to understand society and interact with sociology people when conducting research.

An aquaponic system is a complex system that is also shown to be expensive to establish at least at a fully operational subsistence scale [15]. In the aquaponic system, materials used to manage the system requires skills and knowledge between medium to strong [70]. As a result, if the aquaponic system is to make a difference in people's life in South Africa, social sustainability is the crucial factor to consider. There 
are standard principles underpinning social sustainability to evaluate and guide any social intervention for sustainability, these are, (a) human safety and health must be promoted and protected comprehensively, (b) education must be provided, warranting individual identity and development, (c) culture must be promoted, together with the protection and improvement of social standards and resources that constitute social capital (d) equivalent rights and legal safety must be certain to everyone, with specific attention to equivalent rights for men and women, equivalent rights and security for minorities, including respect for human dignity and rights and lastly (e) solidarity must be promoted between and within generations and also the global level [65].

The aquaponic system is outlined in the various literature to name but few $[14,15]$ as the sustainable system that is representing a sustainable ecological model. Hence, for the aquaponic system to be recorded as sustainable it has to meet most condition set in each sustainability component (Environment, Economics, and Society) when evaluated. Beside guidelines there are other tools to assess sustainability of agricultural systems; from the list include emergy, emergy is one of the accurate because it has applicable software models for simulation purposes.

Globally, youth involvement in agriculture has been decreasing significantly, particularly in RSA [27]. This is attributed to poor payments, being soil dirty and unpleasant social perceptions and stigma toward young farm workers, inevitable, this has resulted in decline, failure and collapse of agricultural projects in South Africa [27]. Aquaponics present a potential opportunity for youth involvement into agriculture practice and development, which could be a kick start for sustainable economic freedom and development [1]. There was a hypothesis notion that said, if agriculture could be made innovative, sophisticated, adventurous and simple, youth involvement in agriculture could increase significantly [64]. Hence, achieve sustainable food security and economic production. Aquaponic present that possible opportunity in South African society, since aquaponics is less dirty contagious because of it soilless nature, and is fun too, this is explained by majority of aquaponic systems across the world being categorized as hobby scale [70]. If all sustainability components could be achieved, it will present a perfect platform for sustainable aquaponic development programmes to be achieved, hence, prompts better opportunity for a food secure society.

\section{Role of Aquaponics System to Food Security}

Food security exists when all people, at all times, have physical and economic access to sufficient, safe and nutritious food that meets their dietary needs and food preferences for an active and healthy life [17]. There are four food security pillars which define, defend and measure food security status locally, nationally and internationally. These are food availability, food accessibility, food utilization and food stability [71]. Food availability is achieved when nutritious food is available at all times for people to access. Food accessibility is achieved when people at all-time have economic ability to obtain nutritious food available according to their dietary preferences. Food utilization is achieved when all food consumed is absorbed and utilized by the body to make healthy active life, food stability is achieved when other pillars are achieved [27].

On top of food and nutrition security agenda/resolution is to achieve a method or programme that can directly support vulnerable people to poverty with opportunity to realize food security, particularly nutrition security. Aquaponics system provide that excel opportunity because it produces fish and vegetables at the same time, most of all can address food sovereignty for food security if aquaponics system can be implemented as a programme for local people to own these system, hence, control the means of production of the food they directly eat. In turn boost food and nutrition status of society, because fish is a significant source of protein, essential amino acids, and vitamins, which are an import for food security [2]. Even in small quantities, fish can improve dietary quality by contributing essential amino acids often missing or underrepresented in vegetable-based diets [20]. In addition to proteins, fish and fish oils are the lucrative source of omega three fatty acids that are most crucial for normal brain development in unborn babies and infants [1]. However, the USAID concern is that less nutritious fish are available to the poor as a result of lack of economic access related to lack of affordability and buying power [1]. In this regard, if aquaponics could be implemented in household's level, it present a perfect opportunity for sustainable meat (fish) and greens (vegetables) production, which in particular is convenient to enhance, food, nutrition and water security, particularly in South Africa [27].

However, the technology associated with soilless systems, aquaponics in particular, is complex [20]. It requires the ability to simultaneously manage the production and marketing of two different agricultural products. Hence, a successful aquaponics enterprise requires special training, skills, or an easy to use computer control system $[7,15]$. This then, suggests the need for capacity development training or skilled development programmes before implementing aquaponic projects. Hence, if food security is to be achieved via aquaponics production, skills development must be implemented first. Nevertheless, aquaponics presents a perfect opportunity for sustainable food production for food security.

\section{General Discussion}

The greater need to increase food production is in response to the increases in population, which has resulted in greater use of water and synthetic fertilizer in agriculture. This has resulted in instability within between agricultural biodiversity which is needed for sustainable agricultural production. The quest to address the challenge has resulted in the exploration of soilless production systems, particularly aquaponics. Aquaponic system is a mutual benefiting system, where fish and vegetables are produced at the same time through linking aquacultural fish waste as a natural nutrient source to grow plants in hydroponic culture in a circulating system, in return plants cleans water by taking up most total nitrogen to maintain water quality for fish wellbeing. However, aquaponics is still the emerging practice in Africa including SA, this than suggest that, there is a limited information, if any, to help aquaponic farmers to make best decision for their system. Nevertheless, aquaponics is shown to have high potential to address water scarcity and food and nutrition insecurity. This is because aquaponics saves water more than conventional agriculture in addition provide platform for nutrient cycle and opportunity for organic food production. However, the difficult to manage two agricultural enterprises (fish and vegetables) poses a major challenge.

\section{Conclusion}

Thus, suggest the need for model development intervention to simplify the production of aquaponic system, hence to benefit the society. However, this suggests that if a majority of SA people were to benefit from aquaponic system, greater stakeholder intervention is needed. Tilapia is the mostly farmed species in aquaponic in most aquaponics, because of its ability to withstand harsh and various $\mathrm{pH}$ and temperature ranges and is easy to breed and manage. Aquaponics foods are easily marketable because food produces from aquaponics are healthier than most production systems including field production. 
Citation: Mchunu N, Lagerwall G, Senzanje A (2017) Food Sovereignty for Food Security, Aquaponics System as a Potential Method: A Review. J Aquac Res Development 8: 497. doi: 10.4172/2155-9546.1000497

\section{Conflict of Interest}

There are no conflicts of interest existing in any way between the authors and the funders of the project.

\section{References}

1. USAID (2013) Sustainable fisheries and responsible aquaculture: A Guide for USAID Staff and Partners. University of Rhode Island/Coastal Resources Centre, Rhode Island, USA

2. FAO (2015) Land and property rights: Junior Farmer Field and Life School, Facilitator's guide. Aquaculture, Rome, Italy.

3. Mabhaudhi T, Modi AT, Beletse YG (2013) Response of taro (Colocasia esculenta $\mathrm{L}$. Schott) landraces to varying water regimes under a rain shelter. Agric Water Manag 121: 102-112.

4. Molobela IP, Sinha P (2011) Management of water resources in South Africa: A review. African J Environ Sci Technol 5: 993-1002.

5. Murugan AV, Swarnam TP (2013) Nitrogen release pattern from organic manures applied to an acid soil. J Agric Sci 5: 174

6. Rakocy JE, Masser MP, Losordo TM (2006) Recirculating aquaculture tank production systems: Aquaponics - Integrating fish and plant culture. SRAC Publications, Canada.

7. Lennard W (2004) Aquaponics research at Melbourne, Australia. Aquaponics J 18-24.

8. Ibironke OA (2013) Glasshouse production of vegetables and ornamentals for agricultural productivity in Nigeria. World J Agric Sci 1: 113-119.

9. Kratky BA (2009) Three non-circulating hydroponic methods for growing lettuce. Acta Hortic 843: 65-72.

10. Lam SS, Ma NL, Jusoh A, Ambak MA (2015) Biological nutrient removal by recirculating aquaponic system: Optimization of the dimension ratio between the hydroponic and rearing tank components. Int Biodeterior Biodegrad 102 107-115.

11. Schouw NL, Tjell JC (2003) Social and institutional feasibility of recycling nutrients in waste in Southern Thailand. Waste Manag Res 21: 393-404.

12. Bonvin C (2013) Recycling of phosphorus and nitrogen from human urine: Evaluation of two urine based fertilizers. Swiss Federal Institute of Technology, Zurich.

13. Nyamangara J, Mtambanengwe F, Musvoto C (2009) Carbon and nitrogen mineralization from selected organic resources available to smallholder farmers for soil fertility improvement in Zimbabwe. African J Agric Res 4: 870-877.

14. Palm HW, Seidemann R, Wehofsky S, Knaus U (2014) Significant factors affecting the economic sustainability of closed aquaponic systems. Part I: System design, chemo-physical parameters and general aspects. AACL Bioflux 7: $20-32$

15. Rakocy J (2007) Ten guidelines for aquaponic systems. Aquaponics J $3^{\text {rd }}$ Quarter 2: 14-17.

16. Lennard BW (2010) A new look at NFT Aquaponics. Aquaponics J 16-19.

17. Allison EH (2011) Aquaculture, fisheries, poverty and food security. Security 61

18. Andersson E (2015) Turning waste into value: Using human urine to enrich soils for sustainable food production in Uganda. J Clean Prod 96: 290-298.

19. Morshuizen TL (2013) The commercial viability of aquaponics. J Chem In Model 53: 1689-1699.

20. FAO (2014) Small-scale aquaponic food production. FAO fisheries and aquaculture technical paper, Rome, Italy.

21. Goddek S, Delaide B, Mankasingh U, Ragnarsdottir K, Jijakli H, et al. (2015) Challenges of sustainable and commercial aquaponics. Sustain 7: 4199-4224.

22. Khater ESG, Bahnasawy AH, Shams AEHS, Hassaan MS, Hassan YA (2015) Utilization of effluent fish farms in tomato cultivation. Ecol Eng 83: 199-207.

23. Lam SS, Ma NL, Jusoh A, Ambak MA (2015) Biological nutrient removal by recirculating aquaponic system: Optimization of the dimension ratio between the hydroponic rearing tank components. Int Biodeterior Biodegrad 102: 107-115.

24. Sace CF, Fitzsimmons KM (2013) Vegetable production in a recirculating aquaponic system using Nile tilapia (Oreochromis niloticus) with and without freshwater prawn (Macrobrachium rosenbergii). Acad J Agric Res 1: 236-250.
25. Roosta HR, Hamidpour M (2011) Effects of foliar application of some macroand micro-nutrients on tomato plants in aquaponic and hydroponic systems. Sci Hortic (Amsterdam) 129: 396-402.

26. Munguia-Fragozo P, Alatorre-Jacome O, Rico-Garcia E, Torres-Pacheco Cruz-Hernandez A, et al. (2015) Perspective for aquaponic systems: "omic" technologies for microbial community analysis. Biomed Res Int 2015: 1-10.

27. Faber M, Witten C, Drimie S (2011) Community-based agricultural interventions in the context of food and nutrition security in South Africa. South African J Clin Nutr 24: 21-30

28. Diver S, Rinehart L (2010) Aquaponics-Integration of hydroponics with aquaculture. Water 28

29. Roosta HR (2014) Comparison of the vegetative growth, eco-physiologica characteristics and mineral nutrient content of basil plants in different irrigation ratios of hydroponic: Aquaponic Solutions. J Plant Nutr 37: 1782-1803.

30. Coolong T (2012) Hydroponic lettuce. Univeristy Kentucky Coop Sxtention Serv p. $1-4$.

31. Monnet F, Vaillant N, Hitmi A, Vernay P, Coudret A, et al. (2002) Treatment of domestic wastewater using the nutrient film technique (NFT) to produce horticultural roses. Water Res 36: 3489-3496.

32. Bugbee B (2004) Nutrient management in recirculating hydroponic culture Acta Hortic 648: 99-112.

33. Rana S, Bag SK, Golder D, Mukherjee A, Pradhan C, et al. (2011) Reclamation of municipal domestic wastewater by aquaponics of tomato plants. Ecol Eng 37: $981-988$

34. Graber A, Antenen N, Junge R (2014) The multifunctional aquaponic system at ZHAW used as research and training lab 245-255

35. Love DC, Fry JP, Li X, Hill ES, Genello L, et al. (2015) Commercial aquaponics production and profitability: Findings from an international survey. Aquaculture 435: 67-74.

36. Graber A, Junge R (2009) Aquaponic systems: Nutrient recycling from fish wastewater by vegetable production. Desalination 246: 147-156.

37. Liang JY, Chien YH (2013) Effects of feeding frequency and photoperiod on water quality and crop production in a tilapia-water spinach raft aquaponics system. Int Biodeterior Biodegrad 85: 693-700.

38. Rafiee G, Saad CR (2005) Nutrient cycle and sludge production during different stages of red tilapia (Oreochromis sp.) growth in a recirculating aquaculture system. Aquaculture 244: 109-118.

39. Endut A, Jusoh A, Ali N, Nik WBW, Hassan A (2010) A study on the optima hydraulic loading rate and plant ratios in recirculation aquaponic system. Bioresour Technol 101: 1511-1517.

40. Fox BK, Howerton R, Tamaru CS (2010) Construction of automatic bell siphons for backyard aquaponic systems. Biotechnol.

41. Nunes AJP, Marcelo VCS, Browdy CL, Vazquez-Anon M (2014) Practica supplementation of shrimp and fish feeds with crystalline amino acids. Aquaculture 431: 20-27.

42. Wortman SE (2015) Crop physiological response to nutrient solution electrica conductivity and $\mathrm{pH}$ in an ebb-and-flow hydroponic system. Sci Hortic (Amsterdam) 194: 34-42.

43. Pardossi A, Malorgio F, Incrocci L, Campiotti CA, Tognoni F (2002) A comparison between two methods to control nutrient delivery to greenhouse melons grown in recirculating nutrient solution culture. Sci Hortic (Amsterdam) 92: 89-95.

44. Buzby KM, Lin LS (2014) Scaling aquaponic systems: Balancing plant uptake with fish output. Aquac Eng 63: 39-44.

45. Popma T, Masser M (1999) Tilapia life history and biology. South Reg Aquac Cent.

46. Rakocy JE (1989) Tank culture of Tilapia. SRAC Publ 17: 523-529.

47. Brummett R, Ponzoni R (2009) Concepts, alternatives, and environmental considerations in the development and use of improved strains of tilapia in African aquaculture. Rev Fish Sci 17: 70-77.

48. Hu Z, Lee JW, Chandran K, Kim S, Brotto AC, et al. (2015) Effect of plan species on nitrogen recovery in aquaponics. Bioresour Technol 188: 92-98. 
Citation: Mchunu N, Lagerwall G, Senzanje A (2017) Food Sovereignty for Food Security, Aquaponics System as a Potential Method: A Review. J Aquac Res Development 8: 497. doi: 10.4172/2155-9546.1000497

Page 9 of 9

49. Johnson C, Albrecht G, Ketterings Q (2005) Nitrogen basics-The nitrogen cycle. Cornell University Coop Exstension p. 1-2.

50. Lund J (2014) Aquaculture effluents as fertilizer in hydroponic cultivation. Swedish Uni 1-19.

51. Brummett RE, Ponzoni RW (2009) Concepts, alternatives, and environmental considerations in the development and use of improved strains of tilapia in African aquaculture. Rev Fish Sci 17: 70-77.

52. Janse JH (1997) A model of nutrient dynamics in shallow lakes in relation to multiple stable states. Hydrobiologia 342: 1-8.

53. Mazzotti FJ, Vinci JJ (2007) Validation, verification, and calibration using standardized terminology when describing ecological models. University of Florida, IFAS Ext p. 1-2.

54. Daggupati P, Yen H, White MJ, Srinivasan R, Arnold JG, et al. (2015) Impact of model development, calibration and validation decisions on hydrological simulations in West Lake Erie Basin. Hydrol Process 29: 5307-5320.

55. Schieritz N, Milling $P$ (2003) Modeling the forest or modeling the trees a comparison of system dynamics and agent-based simulation. Proc $21^{\text {st }}$ Int Syst Dyn Soc 1-15

56. Gounder $P$ (2006) Modelling the effects of textile dyestuffs on the performance of a municipal co-operation.

57. Mabhaudhi T (2012) Drought tolerance and water-use of selected South African landraces of Taro (Colocasia esculenta L. Schott) and Bambara Groundnut (Vigna Subterranea L. Verdc). University of KwaZulu - Natal.

58. Birkett S, De Lange K (2001) A computational framework for a nutrient flow representation of energy utilization by growing monogastric animals. $\mathrm{Br} \mathrm{J}$ Nutr 86: 661-674.

59. Trucano TG, Swiler LP, Igusa T, Oberkampf WL, Pilch M (2006) Calibration, validation, and sensitivity analysis: What's what. Reliab Eng Syst Saf 91: 1331-1357.
60. Arnold JG, Moriasi DN, Gassman PW (2012) Swat: Model use, calibration and validation. Asabe 55: 1491-1508.

61. Statistics of South Africa (2014) Poverty trends in South Africa: An examination of absolute poverty between 2006 and 2011

62. Buenfil AA, Olukunle O (2015) Integrated aquaculture: A tool for sustainable development/food security and poverty alleviation in achieving MDG's goals. Rep Opin 1: 1-8.

63. Christian B, Laurence G, Olivier K, Girardin P, Galan M, et al. (2009) Comparison of methods to assess the sustainability of agricultural systems. A review. Agron Sustain Dev 29: 223-235.

64. Burns TR (2012) Sustainable development: Sociological perspectives. Int Sociol Assoc 34

65. Ochsenbein G, Wachter D (2004) Sustainability assessment: Conceptua framework and basic methodology. Fed Off Spat Dev p. 1-62.

66. Doualle B, Medini K, Boucher X, Laforest V (2015) Investigating sustainability assessment methods of product-service systems. Procedia CIRP 30: 161-166.

67. Connolly K, Trebic T (2010) Optimization of a backyard aquaponic food production system p. 1-74.

68. White K, O'Niell B, Tzankova Z (2004) At a crossroads: Will aquaculture fulfi the promise of the blue revolution? A SeaWeb Aquac Clear Rep 17.

69. Turcios AE, Papenbrock J (2014) Sustainable treatment of aquaculture effluents-What can we learn from the past for the future? Sustain 6: 836-856.

70. Love DC, Fry JP, Li X, Hill ES, Genello L, et al. (2015) Commercial aquaponics production and profitability: Findings from an international survey. Aquaculture 435: 67-74.

71. Drangert JO (1998) Fighting the urine blindness to provide more sanitation options. Water SA 24: 157-164. 